\title{
Raising local standards of infection control in Cameroon
}

\author{
Nkwan Jacob Gobte \\ Banso Baptist Hospital, Cameroon \\ doi:10.3396/ijic.V4s1.019.08
}

\begin{abstract}
The team at Banso Baptist Hospital in Cameroon has introduced a number of improvements in local infection control standards and has succeeded in creating a safer and more conducive environment for staff and patients. Greater team spirit and persistent efforts have helped raise housekeeping standards and cleaning has become a regular feature across the hospital. The introduction of a sharps and waste disposal system has resulted in the reduction of needle-stick injuries among staff.
\end{abstract}

\section{Introduction}

The Cameroon has a population of just over 17 million and a climate that varies from tropical to semi-arid and hot. The prevalence of HIV/AIDS brings lower life expectancy (51.16 years), higher infant mortality (63.52 deaths/1,000 live births), higher death rates and lower population and growth rates ${ }^{1}$ than in countries in the Western world. In addition to HIV, the risk of infectious disease is very high, including bacterial diarrhoea, hepatitis A and typhoid fever (food or waterborne diseases); malaria and yellow fever; schistosomiasis and meningococcal meningitis. ${ }^{1}$

The 248-bed Banso Baptist Hospital is located in the northwest province of Cameroon, West Africa. As a tertiary referral hospital, the hospital has an annual outpatient attendance of 66,000 . It is one of three large hospitals run by the Cameroon Baptist Convention Health Board (CBCHB).
In 2002, an infection control team of ten was formed at the hospital. Although housekeeping and waste disposal in Banso Baptist Hospital were above local standards, following the creation of the Infection Control Programme, it was noted that improvements could be made.

\section{Challenges}

- Cleaning was irregular and below standards in some areas.

- Needle stick injuries were high - nurses routinely recapped used needles and there was multiple handling of needles (cutting, sharpening, etc) before disposal.

- Injection wastes were disposed of in a poorly-fenced pit where school children picked up used syringes.

- No formal training programme existed for housekeeping personnel.

\section{Corresponding author}

Nkwan Jacob Gobte, Banso Baptist Hospital, Cameroon 


\section{Method}

At regular meetings with the hospital administration, the team planned, implemented and reviewed strategies. Minutes were circulated to the team members and to the hospital administration and announcements were made during staff meetings and through letters and notices.

\section{Waste and sharps management}

- Disposable syringes/needles were introduced.

- No routine recapping of needles (nurses have been taught to use the one-handed method if they must recap).

- Needles/syringes discarded in sharps containers immediately after use.

- Modern incinerator constructed.
- Sharps containers are emptied directly into the incinerator exclusively by nurses and no longer by housekeeping personnel.

- Sharps are burnt in the incinerator and the remains emptied in a well constructed burial pit.

- Garbage cans are raised off the ground (out of the reach of stray animals), emptied daily or when $3 / 4$ full and cleaned.

- Other solid wastes are also burnt in the incinerator.

\section{Sanitation Day, inspection and trophy}

The team launched a Hospital Sanitation day on 16 April 2005. The third Saturday of every month is now the hospital's official sanitation day. The infection control nurse ensures that all staff and departments are actively involved.
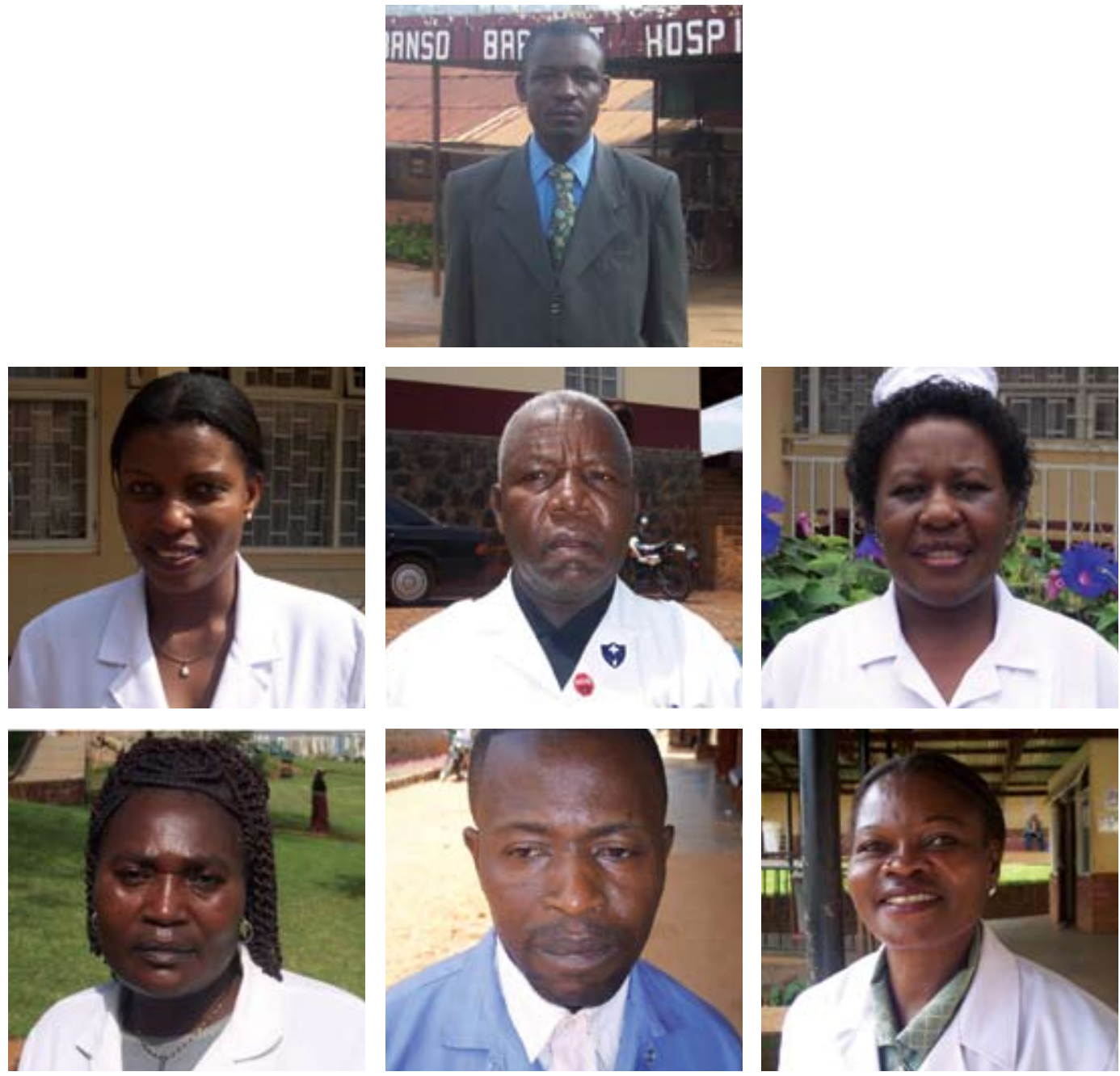

The team, top: Nkwan Jacob Gobte, middle row (left to right): Sandra Ayuk, Peter Tata, Julia Ngoran. Bottom row (left to right): Esther Ngoh, Emmanuel Ngwang, Margaret Ngwayu. Not in photo: Vincent Temi, Japheth Tavnjong, Godheart Kpuyuf 
The infection control team has been divided into groups of two and a number of units have been assigned to each group to monitor housekeeping activities. This includes the development of a housekeeping checklist according to infection control standards. Quarterly inspection and grading of the units is undertaken using the checklist.

To minimise bias, two people per team grade independently. The average of their marks forms the final mark for the unit. Shields (trophies) are awarded to the three cleanest units. Results are announced at staff meetings and on the bulletin boards.

\section{Infection control training programme}

A training manual has been developed for housekeeping staff including points such as:

- The importance and purpose of infection prevention

- Hand hygiene

- Waste management

- Housekeeping

- Glove use

All newly recruited nurses receive a 10 -hour orientation on infection prevention.

\section{Results}

- The incidence of needle stick injuries has reduced from 16 in 2004 to seven in 2005.

- Glove use has increased.

- Greater team spirit and persistent work has raised housekeeping standards to an estimated $80 \%$.

- Cleaning has become total and regular in all areas.

- Thesanitation trophy has broughtaboutbehavioural change in all staff.

- Over 250 staff has been trained in basic infection prevention principles.

The hospital won the Cameroon Baptist Convention Health Board cleanest institution award in 2005.

\section{Conclusions}

Team spirit leads to greater efficiency and there is no great achievement without persistent work. Change is also easy and better appreciated if it comes from within.

\section{References}

1. ClA - The World Factbook https://www.cia.gov/library/publications/the-world-factbook. 